\title{
Overweight and Obese Patients
}

\author{
Claudia Langebrake
}

\subsection{Introduction}

"More obese people in the world than underweight" was the headline on BBC News on April 1, 2016. This statement is based on a study comparing the prevalence of BMI categories of more than 19.2 million adult participants in 186 of 200 countries (N. C. D. Risk Factor Collaboration 2016). Comparing the age-standardised mean BMI by country in 1975 and 2014, there is a significant increase in both men (21.7 vs $24.2 \mathrm{~kg} / \mathrm{m}^{2}$ ) and women (22.1 vs $24.4 \mathrm{~kg} / \mathrm{m}^{2}$ ). Looking for the proportion of overweight in selected industrialised countries, it is estimated that the prevalence of overweight and obesity in the USA will exceed $70 \%$ in 2020 , followed by England and Australia. Korea, France and Italy are projected to have less than $50 \%$ of the population being overweight (Lyman and Sparreboom 2013).

Obesity is associated with a significant increase in morbidity (including metabolic diseases and cancer) and mortality. It has been estimated that worldwide 481,000 (3.6\%) of all new cancer cases in 2012 were attributable to excess body mass index (BMI) (Arnold et al. 2015).

C. Langebrake $(\bowtie)$

Department of Stem Cell Transplantation and Hospital Pharmacy, University Medical Centre Hamburg-Eppendorf, Hamburg, Germany e-mail: c.langebrake@uke.de

\subsubsection{Definitions and Size Describers of Obesity}

Classification of overweight and obesity is usually based on BMI that is calculated using height and weight of an individual. The World Health Organization (WHO), defines adults according to their BMI as:

- Normal weight with $18.5-24.9 \mathrm{~kg} / \mathrm{m}^{2}$

- Overweight with $25-29.9 \mathrm{~kg} / \mathrm{m}^{2}$

- Obese with $\geq 30 \mathrm{~kg} / \mathrm{m}^{2}$

However, one has to keep in mind that although BMI has been shown to correlate with SC fat (but not with percentage body fat), in individuals with greater muscle mass, women or the elderly, BMI might not be the best describer, as muscle mass is more dense than fat mass. In those people, percent body fat would better describe body composition, but direct measurement is usually not readily available as it requires advanced technical equipment (e.g. hydrodensitometry, skinfold measurement, bioelectrical impedance analysis or dual-energy X-ray absorptiometry) (Hanley et al. 2010). As a consequence, indirect measures of body composition, like BMI or ideal body weight (IBW), remain the standard, as they are easy to calculate. 


\subsection{Influence of Overweight and Obesity on the Pharmacokinetics of Drugs}

Obesity is associated with physiological changes that can alter the pharmacokinetic parameters of many drugs (Hanley et al. 2010; Green and Duffull 2004; Han et al. 2007; Alobaid et al. 2016). Observed physiological changes in obese patients influencing pharmacokinetic behaviour of drugs and resulting consequences for drug dosing are summarised in Table 67.1.

Nevertheless, it has to be kept in mind that the effects of physiological changes are usually drug specific and that for the majority of drugs both pharmacokinetic and clinical data in obese patients are sparse. Due to unusual distribution processes, the kinetics of drugs is difficult to predict in obese patients.

The impact of obesity on GFR as well as on tubular secretion is not completely understood. Discrepant results regarding GFR in obese as compared with normal-weight individuals might be explained by estimating GFR using serum creatinine, as no instrument has been validated for obesity. Especially, if using weight-based formulas like the widespread Cockroft-Gault formula, GFR will be overestimated if total body weight is used, but underestimated if ideal body weight is used. But also the use of weight-independent formulas, as MDRD (Modification of Diet in Renal Disease) or CKD-EPI (Chronic Kidney Disease Epidemiology Collaboration), which has been shown to result in more reliable estimates, has limitations: As the GFR is provided in $\mathrm{ml} /$ $\mathrm{min} / 1.73 \mathrm{~m}^{2}$, the possibly incorrect calculation of body surface area in the obese might negatively influence the results.

Taken together, there is only limited evidencebased information about drug clearance in obese patients due to restrictions of clinical trials and the lack of pharmacokinetic (PK) analyses. It is important to remember that there is no singlesize descriptor for all drugs.

Table 67.1 Physiological changes in obese individuals influencing pharmacokinetics of drugs

\begin{tabular}{|c|c|c|}
\hline & Changes in obese patients & Consequences for drug dosing \\
\hline Absorption & $\begin{array}{l}\text { - Increased gastrointestinal blood flow } \\
\text { - Accelerated gastric emptying }\end{array}$ & $\begin{array}{l}\text { - Only little data on oral bioavailability } \\
\text { - For a couple of drugs including CSA, midazolam } \\
\text { or propranolol, no differences in oral } \\
\text { bioavailability have been observed }\end{array}$ \\
\hline Distribution & $\begin{array}{l}\text { - Hydrophilic drugs: Vd is similar in normal- } \\
\text { weight and obese patients } \\
\text { - Moderate or high lipophilic drugs: significant } \\
\text { differences in Vd } \\
\text { - Tissue blood flow may be reduced } \\
\text { - Obesity does not appear to have impact on } \\
\text { plasma protein binding }\end{array}$ & $\begin{array}{l}\text { - Vd is important for the determination of a loading } \\
\text { dose, in order to achieve a rapid and adequate } \\
\text { exposition } \\
\text { - Vd changes are drug specific (attributable to the } \\
\text { physicochemical properties of the drug) }\end{array}$ \\
\hline $\begin{array}{l}\text { Clearance } \\
\text { (renal and } \\
\text { hepatic) }\end{array}$ & $\begin{array}{l}\text { - Altered hepatic blood flow } \\
\text { - TBW-proportional increase in phase II } \\
\text { metabolism } \\
\text { - GFR and renal perfusion similar, but } \\
\text { imprecision in GFR estimation } \\
\text { (see text above) } \\
\text { - Obese individuals exhibit higher absolute } \\
\text { drug clearance } \\
\text { - Clearance does not increase linearly with } \\
\text { TBW } \\
\text { - Clearance and lean body weight are linearly } \\
\text { correlated }\end{array}$ & $\begin{array}{l}\text { - Elimination of hydrophilic and extensively renally } \\
\text { cleared drugs mainly depends upon renal function } \\
\text { - No apparent relationship between lipophilicity } \\
\text { and clearance mechanism } \\
\text { - Essential parameter to determine maintenance } \\
\text { dose } \\
\text { - Physicochemical attributes of drugs have little } \\
\text { impact on clearance }\end{array}$ \\
\hline
\end{tabular}

GFR glomerular filtration rate, $T B W$ total body weight, $V d$ volume of distribution 


\subsection{Recommendations for Drug Dosing}

Besides the above-described physicochemical attributes and pharmacokinetic (PK) properties, recommendations from the literature and plasma concentration monitoring are important to determine drug dosing in morbidly obese patients (Hanley et al. 2010; Green and Duffull 2004; Han et al. 2007).

\subsubsection{Which Weight to Use for Calculation?}

For some drugs, the use of adjusted ideal body weight (AIBW) resulted in similar drug exposure in obese as compared to normal-weight patients (Pai and Bearden 2007; Polso et al. 2014; Bearden and Rodvold 2000): This is, for example, true for aminoglycosides, acyclovir (Turner et al. 2016) or liposomal AmB. AIBW is calculated by adding $25-40 \%$ of the difference between total body weight (TBW) and IBW to the IBW. This method is also well examined using population PK models for busulfan (Nguyen et al. 2006). On the other hand, initial vancomycin dosing should be based on TBW with subsequent therapeutic drug monitoring (Polso et al. 2014; Rybak et al. 2009). However, for many drugs the optimal basis for dose calculation has still to be determined.

\subsubsection{Impact on Drug Dosing of Chemotherapy}

The majority of dosing recommendations in obese patients exist for antimicrobial drugs (Alobaid et al. 2016; Pai and Bearden 2007; Polso et al. 2014; Bearden and Rodvold 2000; Falagas and Karageorgopoulos 2010) and for conventional chemotherapy (Griggs et al. 2012). The American Society of Clinical Oncology (ASCO) published the following main statements in 2012 guidelines:
- Dose should be selected according to body surface area (BSA) using actual body weight.

- Dose reductions should be based on toxicity and comorbidities independent of the obesity status.

- There is no evidence that obese patients experience increased toxicity when actual weight is used for calculation of chemotherapy.

However, some limitations have to be kept in mind, as (1) there are no RCTs comparing actual body weight with other adjusted dosing approaches in obese patients, (2) recommendations are based on subgroup analyses of obese patients from RCTs or observational studies using actual versus adjusted weight calculation and (3) there are no recommendations for HSCT conditioning.

One case report described drug dosing morbidly of an obese patient undergoing allo-HSCT (Langebrake et al. 2011). Here it was observed that for hydrophilic and extensively renally cleared drugs, standard dosages for adult patients or dosing based on ideal body weight can be used. For more lipophilic drugs like CSA or digitoxin, it could be shown that after achieving sufficient plasma levels using high initial doses, maintenance doses similar to those used in normal-weight patients are sufficient. Monitoring of plasma concentrations is highly recommended for drugs with a narrow therapeutic index.

\subsubsection{Preparative Regimens Prior to HSCT}

In patients undergoing auto- or allo-HSCT, specific features and purposes have to be taken into account. In auto-HSCT, high-dose chemotherapy aims to reduce tumour burden, while in alloHSCT, therapeutic effect is based on donor immune cells and myeloablation.

The ASBMT reviewed the current published literature on dosing of pharmacologic agents used for HCT preparative regimens in obese 
patients in 2014. They concluded that dose adjustments were usually performed empirically or have been extrapolated from published data in non-transplant patients. Therefore, evidence for clear standards or dosing guidelines are currently not available as there are insufficient data to determine optimal drug dosing in obese patients undergoing HSCT (Bubalo et al. 2014). Nevertheless, consensus dosing recommendations were given (see Table 67.2).

Recently, the approach to use AIBW-based BSA for dose calculation of MEL prior to autoHSCT has been shown to be non-inferior as compared to the nonobese population in terms of 3-year event-free survival (Shultes et al. 2018).

Even for ATG, TBW for dose calculation is recommended by ASBMT. However, from a PK point of view, it would be more reasonable to use the IBW, as ATG has a volume of distribution that is almost equal to the whole blood volume. Recently, it has been proposed to rather base ATG dosing on absolute lymphocyte count, as this is the target of ATG (Kennedy et al. 2018).
Reports of obese patients undergoing HCT are challenging to interpret because of the heterogeneity of obesity definitions, underlying diseases, graft sources and chemotherapy regimens employed. Compared with normal-weight patients, it appears that obese patients undergoing allo-HSCT have a higher risk of non-relapse mortality and inferior survival, whereas those receiving auto-HSCT appear to have equivalent outcomes. Another important limitation for interpretation of published data is that there is no consistent standard for calculating chemotherapy dose in this group. Therefore, it is recommended that future studies utilise more consistent and biologically relevant definitions of obesity and that the PK and pharmacodynamics of specific conditioning regimens be studied (Weiss et al. 2013). In clinical practice, about $80 \%$ of HSCT centres routinely perform dose adjustment for obesity; however, the methods used for determining the weight for chemotherapy calculation are different among the transplant centres (ShemTov et al. 2015).

Table 67.2 Overview of volume of distribution

\begin{tabular}{|c|c|c|}
\hline Drug & $\mathrm{Vd}^{\mathrm{a}}$ & Recommendation (ASBMT 2014) Bubalo et al. (2014) \\
\hline Alemtuzumab & Low & Flat dosing \\
\hline Amsacrine & High & n.a. \\
\hline ATG & Low & TBW (for mg/kg) \\
\hline Busulfan & Medium & $\begin{array}{l}\text { - AIBW25 in adults (obese and nonobese) for } \mathrm{mg} / \mathrm{kg} \\
\text { - TBW (for BSA) } \\
\text { - PK targeting for regimens }>12 \mathrm{mg} / \mathrm{kg} \text { PO equivalent }\end{array}$ \\
\hline Carboplatin & Low & TBW (for BSA) \\
\hline Carmustine & High & TBW (for BSA), unless $>120 \%$ IBW, then AIBW 25 \\
\hline Clofarabine & High & TBW (for BSA) \\
\hline Cyclophosphamide & Medium & $\begin{array}{l}-200 \mathrm{mg} / \mathrm{kg} \text { : lesser of IBW or TBW } \\
-120 \mathrm{mg} / \mathrm{kg} \text { : either IBW or TBW until }>120 \% \text { IBW and then dose based } \\
\text { on AIBW25 (former is preferred for adults, latter for children) }\end{array}$ \\
\hline Cytarabine & High & TBW (for BSA) \\
\hline Etoposide & Low-medium & $\begin{array}{l}\text { - AIBW25 for } \mathrm{mg} / \mathrm{kg} \\
\text { - TBW (for BSA) }\end{array}$ \\
\hline Fludarabine & High & TBW (for BSA) \\
\hline Melphalan & Medium & TBW (for BSA) \\
\hline Pentostatin & Medium & TBW (for BSA) \\
\hline Thiotepa & Medium & TBW (for BSA), unless $>120 \%$ IBW, then AIBW 40 for BSA \\
\hline Treosulfan & Medium & n.a. \\
\hline
\end{tabular}




\section{Key Points}

- Obesity is associated with a significant increase in morbidity (including metabolic diseases and cancer) and mortality.

- Indirect measures of body composition, like BMI or ideal body weight, remain the standard, as they are easy to calculate.

- There is only limited evidence-based information about drug clearance in obese patients due to restrictions of clinical trials and the lack of pharmacokinetic analyses.

- Evidence for clear standards or dosing guidelines are currently not available as there are insufficient data to determine optimal drug dosing in obese patients undergoing HSCT.

- Despite that, in clinical practice, about $80 \%$ of HSCT centres routinely perform dose adjustment for obesity. However, the methods used for determining the weight for chemotherapy calculation are different among the transplant centres.

\section{References}

Alobaid AS, Wallis SC, Jarrett P, et al. Effect of obesity on the pharmacokinetics of antimicrobials in critically ill patients: a structured review. Int J Antimicrob Agents. 2016;47:259-68.

Arnold M, Pandeya N, Byrnes G, et al. Global burden of cancer attributable to high body-mass index in 2012: a population-based study. Lancet Oncol. 2015;16:36-46.

Bearden DT, Rodvold KA. Dosage adjustments for antibacterials in obese patients: applying clinical pharmacokinetics. Clin Pharmacokinet. 2000;38:415-26.

Bubalo J, Carpenter PA, Majhail N, et al. Conditioning chemotherapy dose adjustment in obese patients: a review and position statement by the American Society for Blood and Marrow Transplantation practice guideline committee. Biol Blood Marrow Transplant. 2014;20:600-16.

Falagas ME, Karageorgopoulos DE. Adjustment of dosing of antimicrobial agents for bodyweight in adults. Lancet. 2010;375:248-51.

Green B, Duffull SB. What is the best size descriptor to use for pharmacokinetic studies in the obese? Br J Clin Pharmacol. 2004;58:119-33.

Griggs JJ, Mangu PB, Temin S, Lyman GH, et al. Appropriate chemotherapy dosing for obese adult patients with cancer: American Society of Clinical Oncology clinical practice guideline. J Clin Oncol. 2012;30:1553-61.

Han PY, Duffull SB, Kirkpatrick CM, Green B. Dosing in obesity: a simple solution to a big problem. Clin Pharmacol Ther. 2007;82:505-8.

Hanley MJ, Abernethy DR, Greenblatt DJ. Effect of obesity on the pharmacokinetics of drugs in humans. Clin Pharmacokinet. 2010;49:71-87.

Kennedy VE, Chen H, Savani BN, et al. Optimizing antithymocyte globulin dosing for unrelated donor allogeneic hematopoietic cell transplantation based on recipient absolute lymphocyte count. Biol Blood Marrow Transplant. 2018;24:150-5.

Langebrake C, Bernhardt F, Baehr M, et al. Drug dosing and monitoring in obese patients undergoing allogenic stem cell transplantation. Int J Clin Pharm. 2011;33:918-24.

Lyman GH, Sparreboom A. Chemotherapy dosing in overweight and obese patients with cancer. Nat Rev Clin Oncol. 2013;10:451-9.

N. C. D. Risk Factor Collaboration. Trends in adult bodymass index in 200 countries from 1975 to 2014: a pooled analysis of 1698 population-based measurement studies with 19.2 million participants. Lancet. 2016;387:1377-96.

Nguyen L, Leger F, Lennon S, Puozzo C. Intravenous busulfan in adults prior to haematopoietic stem cell transplantation: a population pharmacokinetic study. Cancer Chemother Pharmacol. 2006;57:191-8.

Pai MP, Bearden DT. Antimicrobial dosing considerations in obese adult patients. Pharmacotherapy. 2007;27:1081-91.

Polso AK, Lassiter JL, Nagel JL, et al. Impact of hospital guideline for weight-based antimicrobial dosing in morbidly obese adults and comprehensive literature review. J Clin Pharm Ther. 2014;39:584-608.

Rybak M, Lomaestro B, Rotschafer JC, et al. Therapeutic monitoring of vancomycin in adult patients: a consensus review of the American Society of HealthSystem Pharmacists, the Infectious Diseases Society of America, and the Society of Infectious Diseases Pharmacists. Am J Health Syst Pharm. 2009;66:82-98.

Shem-Tov N, Labopin M, Moukhtari L, et al. Chemotherapy dose adjustment for obese patients undergoing hematopoietic stem cell transplantation: a survey on behalf of the Acute Leukemia Working Party of the European Society for Blood and Marrow Transplantation. Oncologist. 2015;20:50-5.

Shultes KC, Arp C, Stockerl-Goldstein K, et al. Impact of dose-adjusted melphalan in obese patients undergoing autologous stem cell transplantation. Biol Blood Marrow Transplant. 2018;24:687-93.

Turner RB, Cumpston A, Sweet M, et al. Prospective, controlled study of acyclovir pharmacokinetics in obese patients. Antimicrob Agents Chemother. 2016;60:1830-3.

Weiss BM, Vogl DT, Berger NA, et al. Trimming the fat: obesity and hematopoietic cell transplantation. Bone Marrow Transplant. 2013;48:1152-60. 
Open Access This chapter is licensed under the terms of the Creative Commons Attribution 4.0 International License (http://creativecommons.org/licenses/by/4.0/), which permits use, sharing, adaptation, distribution and reproduction in any medium or format, as long as you give appropriate credit to the original author(s) and the source, provide a link to the Creative Commons license and indicate if changes were made.

The images or other third party material in this chapter are included in the chapter's Creative Commons license, unless indicated otherwise in a credit line to the material. If material is not included in the chapter's Creative Commons license and your intended use is not permitted by statutory regulation or exceeds the permitted use, you will need to obtain permission directly from the copyright holder.

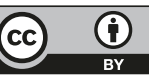

